Made available courtesy of Human Kinetics: http://www.humankinetics.com

***Reprinted with permission. No further reproduction is authorized without written permission from the Human Kinetics.

This version of the document is not the version of record.

Figures and/or pictures may be missing from this format of the document.***

\title{
New Directions in Undergraduate and Graduate Education in Kinesiology and Physical Education
}

\author{
Catherine D. Ennis
}

\begin{abstract}
New opportunities exist in graduate and undergraduate kinesiology programs for both enhancement and innovation. Professional master's degrees prepare students for careers at the intersections of academic disciplines and the business world. Interdisciplinary study can result in opportunities not only for innovative research discoveries, but also for students to find meaningful connections within the kinesiology subdisciplines. Designing core courses for intentional far transfer of fundamental concepts using specific research supported strategies can enhance student satisfaction, retention, and learning.
\end{abstract}

How could a university's $10 \%$ budget increase in 2008 turn into a $10 \%$ budget decrease in 2009? Changes in state funding to higher education institutions happen so quickly with such devastating results that it is hard to anticipate and respond effectively. Economic downturns are not new to universities or to departments of kinesiology. When our personal finances are limited, we find productive ways to spend our time that require minimum funds. This also is true in academic departments, as well, where there are always new ideas and new directions to consider. Although many ideas do not require large sums of money, they do necessitate revisiting our priorities and determining if our programs are meeting the current and future needs of our most valued stakeholders. In this paper I will discuss some strategic initiatives that kinesiology department administrators and faculty can consider to (a) increase the educational value of students' degree experiences, (b) create integrated professional degrees, (c) straighten the path to degree completion, (d) teach interdisciplinary kinesiology, and (e) foster conceptual transfer to attract and retain highly motivated and engaged undergraduate and graduate students.

\section{Educational Value}

In 2010, the educational value of a college education may mean different things to different people. To faculty it can mean opportunities to mentor the next generation of scholars who understand and can apply foundational concepts in the kinesiology

The author (AAKPE Fellow \#381) is with the Dept. of Kinesiology, University of North Carolina at Greensboro. 
disciplines and professions. Faculty members often envision that students will use their kinesiology knowledge to continue on to graduate or medical school. With this academic aim in mind, faculty members focus on providing fundamental and advanced knowledge and skills consistent with an academic understanding of their subject area.

Many of our students (and their parents), however, view an undergraduate or graduate degree as a ticket to a career and, more specifically, a "job" (Lake, 2009). Many undergraduate students eagerly anticipate their licensure as athletic trainers, teachers, personal trainers or physical therapists. This potential mismatch between students' career orientations and faculty's academic vision can create a gap between the educational credentials students want in the short term, and the curriculum faculty values for the long term (Lake, 2009).

These two very different perspectives on the educational value of an undergraduate or graduate degree suggest a shift is occurring in the public's expectation for university degrees. This reflects a change from an academic to a more utilitarian purpose with the potential to reshape the structure and focus of the university degree. Lake (2009) agrees:

Higher education's role in American society is undergoing a seismic shift, similar in magnitude to that experienced in the 1950s and 1960s. The unmistakable trend this time: public demand for greater accountability from colleges for the fulfillment of their core missions and a cry for demonstrable value, results, and efficiency. (para. 6)

During the last fifty years, universities have experienced major increases in student enrollments, large building projects, and increases in alumni giving. Recently, most universities have exceeded their capital fundraising campaigns by millions of dollars. During this time educational costs have shifted silently from state governments to students and families, although increasing family incomes masked some of this change (Lake, 2009). Good economic times also have hidden issues related to degree and university accountability. A thriving economy meant that most graduates with a Bachelor of Science degree were likely to find work in government, education, health care, or business. These jobs came with salaries that reflected the flourishing economic times and with purchasing power to enjoy "the good life." In this economic climate, universities and colleges were perceived to be providing educational value as defined by job placement and generous salaries (Lake, 2009).

Unfortunately, by 2009 the good times had lurched to a halt and many things that families once considered affordable were suddenly out of reach to parents with foreclosed property, dramatic stock portfolio declines, or without employment. Although success on Main Street is still gauged by career and salary, liberal arts degrees and other degrees not linked directly to an occupation have come under greater scrutiny. During times of high unemployment, colleges and universities directly compete in job market preparation with community colleges that offer quick degrees linked directly to a job in high demand or newly emerging fields (e.g., "green" jobs). Community colleges, for example, permit students to live at home, drive short distances, pay lower tuition, and work part- or fulltime to fund training for a new career. In addition, the Obama administration's focus on student loans has changed the lending picture from government, bank-based loans to direct 
lending (Lake, 2009). These new lenders scrutinize students' future potential to repay their loans. Repayment might well hinge on the school-to-work skills that emanate from students' undergraduate or graduate degrees.

\section{Integrated Degrees With a Professional Focus}

At the graduate level, one initiative well under way in the United States to address the need for school-to-work skills is the professional master's degree. These degrees reflect an integrated or interdisciplinary emphasis that combines coursework and experiences from two or more traditional disciplines (Benderly 2009; Schmidt, 2009). Unlike traditional "academic" master's degrees, such as the Master of Science or the Master of Arts degrees, professional master's degrees seek deep integrations of academic knowledge with a business-oriented emphasis.

\section{Professional Master's Degrees}

The Council of Graduate Schools (2009b) has worked with universities and colleges to reconceptualize and promote professional master's degrees. Professional masters, though best known for science/business integrations, also are evolving today in the social sciences and humanities with broadly conceptualized connections between the discipline and government and nonprofit agencies. Fashioned after the MBA that reconceptualized business education in the early 20th century, professional master's in general, and particularly professional science master's (PSM), offer alternative career paths for students who seek advanced training in science, but do not want a career in academia or research (Tobias, 2009).

Instead of pursuing a Ph.D. in a science field, students enrolled in two-year professional science master's (PSM) degrees focus on the intersections between science and management. These degrees emphasize professional or business skills, such as production management and marketing, enhancing students' opportunities for entrepreneurial careers or positions in science-driven, high tech companies. A primary aim of the PSM degrees is

... to engage students with professional goals and help them become scientists uniquely suited to the 21 st century workplace equipped with a deeper and broader scientific knowledge than they acquired with a Bachelor of Science degree and the skills to apply it." (Colwell, 2009, p. 1676)

The Alfred P. Sloan Foundation has provided seed funding for 128 PSM programs in 64 universities in 23 states producing more than 600 graduates each year. The America COMPETES Act (Public Law 110-69) authorizes the National Science Foundation (NSF) to provide grants for the creation and expansion of 200 PSM programs. A secondary aim of the government program is to increase the number of science professionals in the United States. NSF anticipates that PSM degree initiatives will attract talented international students to enhance and expand domestic sciencerelated professions, increasing the number of women, underrepresented minorities, and returning veterans with technical military training in science-related careers. Salaries of individuals with the PSM in science and engineering have grown faster than those of graduates with either science undergraduate or doctoral degrees (Benderly, 2008). 


\section{Hybrid Professionals}

Individuals who pursue the PSM do not seek to become independent scientists, but hybrid professionals, "with one foot in the marketplace and the other in the laboratory" (Tobias, 2009, p. 32). They are the realization of the bench to bedside professionals in demand in a wide range of industries from health insurance to fitness productivity and innovations specialists.

The PSM appears relevant within the kinesiological science and allied health fields. Currently, degrees are available in many related disciplines, including health informatics, health biomechanics, or biohealthmatics, a degree that integrates biotechnology with health care (Fischer \& Glenn, 2009). In kinesiology, we might create PSMs in obesity prevention, healthful aging, and healthful living, for example. These degrees focus on emerging fields at the intersections of traditional disciplines, emphasizing integrations between science and business that might include coursework in business law, technology transfer, project management, intellectual property law, regulatory affairs, entrepreneurship, leadership, or ethics. Degrees emphasize communication and teambuilding skills and require an extensive internship rather than a thesis. Many PSM graduates receive multiple job offers in the mid \$60,000-\$70,000 range (Fischer \& Glenn, 2009).

Although professional science master's degrees seem to be an important "new direction," most research evaluating these programs has been conducted by proponents or individuals connected with or funded by industries that hire these graduates. Thus, they have vested interests in the success of current and future professional degree efforts, and findings should be viewed cautiously. It is clear that the professional master's degree has the potential to attract students with more diverse interests and career goals to graduate degree programs than currently are found in most academic M.S. or Ph.D. degree programs.

\section{Professional Master's Degrees in Service-Oriented Professions}

Professional masters degrees located "at the intersections" of traditional departments and disciplines also are available in service-oriented professions emerging from the kinesiology disciplines. Robert Reich, former secretary of labor and currently a professor at the University of California Berkeley, points out that the typical American purchases or uses a service more than 40 times a day (Fischer \& Glenn, 2009). Degrees, such as the professional service masters, prepare workers to improve productivity and increase innovation in the service sector. These degrees meet "the need to prepare graduate students for jobs that may not exist today. [Degrees] ...focus on interdisciplinary education and 'soft skills' such as problem identification, communication and team work" (Council of Graduate Schools, 2009c, para. 2).

Kinesiology-related careers might begin with a professional service masters with an emphasis in Fitness Productivity and Innovation. Graduates with athletic training or sports medicine credentials might find positions as Sports Medicine Compliance Officers in school districts or with professional sport organizations. In 2009 , more than 250 colleges and universities in more than 50 countries provide master's degrees in service management and engineering. In the United States, for example, the University of Wisconsin-Stout has a bachelor's and master's degree 
in Service Management (Fischer \& Glenn, 2009). Specializations in fitness, sporting event hospitality, and "active" tourism, among others, are ripe for professional service master's degrees. Other professional service master's graduates might monitor efficient operations of emergency rooms, fitness facilities, and health care management. Graduates of these programs use skills associated with deep problem management that require an understanding of economic, technical, psychosocial, and personnel issues that drive or derail service systems.

\section{Professional Master's Degrees in Data Analysis}

Other professional master's degrees relevant to kinesiology-related fields include computational data analysts who might work in health information management, providing leadership in the creation and management of databases and health care delivery systems. Many health-care organizations, the insurance industry, and other for-profit businesses are "drowning in data" (Fischer \& Glenn, 2009, para. 19) produced by batteries of medical tests and exacerbated by government and insurance company codes and pricing structures. The technology challenges generated by the evolution of digital and information resources provide a rich variety of opportunities for individuals with interests in health care who have computer and data management skills.

Unlike in the past when these jobs entailed simple data entry, individuals with professional master's degrees with an emphasis in Data Analysis and Management combine computational science with business degrees. They generate computer software to increase data portability, organize and make sense of data for medical reimbursements, maintain medical record privacy and security, or develop new policy initiatives to address and control burgeoning data collection and management systems (Fischer \& Glenn, 2009). We currently have graduate students who enroll in kinesiology degrees with previous expertise in computational science. Providing opportunities for melding these skills with large database management can assist in monitoring sport performance injuries, aging-related injuries, or medication profiles for national and international databases. Health informatics data analysis degrees can take advantage of the strategic intersections within and among the kinesiology and public health disciplines.

\section{Professional Master's of Arts in Humanities and Social Sciences}

In 2002, the Council of Graduate Schools (2009a) approached the Ford Foundation for a grant to extend professional master's degrees to the humanities and social sciences. The focus was to reform traditional Master of Arts degrees to provide a more focused career orientation, providing highly qualified individuals to fill entry-level positions in business, government, and nonprofit employment sectors. In 2003, the Ford Foundation provided a planning grant to 38 universities to create professional Master of Arts degrees in the humanities and social sciences (Council of Graduate Schools, 2009a). Degrees such as the Professional Master's of Arts (PMA) are offered in a number of disciplines, such as criminal justice (University of Nevada-Las Vegas) and health communications (SUNY-Albany). The Council of Graduate Schools (2009a) will distribute a report on the PMA in the humanities and social sciences in April 2010. 


\section{International Degrees}

Government and education policy makers within the European Union have developed a novel approach to streamlining and coordinating degrees across countries within the European Union (Loades, 2005). A major emphasis of this comprehensive plan is to expand degrees from the traditionally isolated academic focus within a silo or stovepipe discipline to a more comprehensive interdisciplinary approach to education (Glenn \& Fischer, 2009). The Bologna Accord (Wilson, 2005) created a uniform system for structuring degrees and providing a more seamless intersection between disciplines and across degree levels. For example, combined threeyear bachelors and two-year master's degrees have replaced traditional four-year bachelors and one-year master's degrees (Labi, 2009). In addition, students are encouraged to combine courses and experiences from two or more universities in different countries to create a degree that provides optimal access to the most creative and highest quality education (Labi, 2009). See Ross Sanders' paper in this issue for details of the policy and programs that have emerged from the Bologna Accord. It is likely that these initiatives, similar but on a grander scale than consortia developed among American universities, stand to disrupt our parochial definitions of the academic major (see also, DePauw, 2008). The Commission on the Future of Graduate Education sponsored by the Council of Graduate Schools (2009c) is discussing initiatives to enhance the United States' "position in terms of graduate degree attainment and graduate program preeminence as the world becomes more competitive" (bullet 3).

\section{Straightening the Path to Degree Completion}

In a difficult economy when many expensive projects are on hold waiting funding sources, it is prudent to focus on departmental and school initiatives that are less expensive to implement, but pay large dividends. Some of these initiatives involve internal reviews of graduate and undergraduate curricula and program policy to ensure that the student path to each degree is as straight or direct as possible. Because university degrees are expensive and time consuming, faculty and administrators have a compelling responsibility to examine and maintain the degree path quality and integrity to ensure that student effort, time, and money are directed toward knowledge attainment and degree completion.

\section{Curricular Revision}

Often faculty are eager to expend effort on creating new majors, minors, specialization, concentrations, and certificates, but are less willing to devote time later to evaluating these curricula for redundancies or problems with sequencing or prerequisites. New curricula often are created with the hope that they will be revisited within three to five years to evaluate their disciplinary fit and their attractiveness to students. At times, however, these curricula are allowed to run unimpeded and reviewed only in conjunction with larger departmental or school evaluations.

Internal curricular reviews of individual programs are typically less expensive to perform than external reviews and require minimal amounts of faculty time. An internal review conducted with the goal of determining the content actually taught 
in the courses is useful periodically to reevaluate disciplinary knowledge scope and complexity, reconsider faculty perspectives and expertise, reexamine laboratory capacity in light of increasing enrollments, and revise content to reflect students' diverse cultures, interests, and career goals. Providing opportunities for faculty to talk together about their program vision and course intentions greatly enhances curricular coherence. These conversations can lead to adjustments to refine and refocus content coverage, field-based opportunities, and integrative experiences. Efforts to address the perceived strengths and weaknesses of recent graduates can lead to both small- and large-scale modifications at the course and program level. Rapid knowledge development in many disciplines may lead faculty to conclude that adjustments are necessary in course type, prerequisites, sequencing, and frequency.

Curricular decisions always entail questions of educational value and worth. These decisions cannot be answered in isolation, but require referents to a particular place and time. Because there is rarely adequate instructional time to cover all material that instructors believe students should learn, it is essential for administrators and course instructors to identify priorities. The question originally formulated by Herbert Spencer in 1861, "What knowledge is of most worth?" is still central to discussions of curricular priorities, today. We can contextualize this question to make it more relevant by asking, "What knowledge is of most worth at this time, to these stakeholders, at this college/ university, in this state/nation/world?" Thus, curricular innovations or revisions should address questions of educational value and create a coherent, equitable message within our undergraduate and graduate programs that resonates with our stakeholders and energizes our colleagues.

\section{Refreshing the Kinesiology Core}

In most departments of kinesiology the disciplinary core consists of content that faculty perceives to be of great worth. Typically, the kinesiology core represents a group of five to eight, three/four credit courses that reflects the traditional disciplinary divisions of our subject area. All kinesiology students are required to complete a common set of core courses in the areas of history, philosophy, sport and exercise psychology, sociology, motor development, motor learning/control, biomechanics, and exercise physiology. It is prudent periodically to reexamine the common kinesiology coursework core to ensure that current content represents the knowledge "of most worth," appears coherent to our stakeholders, and contributes to student learning in ways that we value.

Currently, there are many challenges to the traditional kinesiology core that faculty should discuss and address. Faculty might begin by asking, "Does the current set of core courses represent our current vision of kinesiology?" If so, is it realistic to continue to require the same courses for all majors in light of increasing enrollments and students' diverse interests? At what point does a common kinesiology core become incoherent to specialized majors? Should all kinesiology core courses have prerequisite courses outside the department to ensure that students enroll in every core course with prior disciplinary knowledge? Should core courses with multiple course prerequisites be privileged over others with no prerequisite courses?

Recently, our tendency to remain secure in our academic research silos also has applied to our core courses. Does our newfound interest in research interdisciplinarity extend to the kinesiology core? Is there an overemphasis on historical content 
divisions within the kinesiology core that reflects our disciplinary silos, limiting our efforts to foster interdisciplinarity within kinesiology? There is no single, right answer to any of these questions. Instead, it is the responsibility of each department chair and faculty to address these questions within their own educational, economic, historical, and futuristic context. Decisions made today will have an impact on the departments' growth, flexibility, and coherence for years to come.

Within undergraduate degree specializations, the time is ripe for faculty to meet to discuss content that currently is presented in lecture, laboratory, discussion, and internships courses. Faculty need to be keenly aware not only of the content that currently is taught but also to identify valid content that is not taught. Described as the "null curriculum" (Flinders, Noddings, \& Thornton, 1986), the content not taught due to lack of time, instructor expertise, equipment, or facilities directly impacts students' opportunities to learn. Internal course reviews within disciplinary specializations also can identify unnecessary redundancies that absorb critical resources while planning for needed content and topic repetition. Planned redundancy is essential for student learning and retention of complex theories and concepts, content taught for intentional transfer, or content that is best understood within the context of meaningful experiences (Alexander, 2006). Program and course reviewers should closely monitor the linkages between foundational concepts and appropriate applications (transfer) to more advanced knowledge and to authentic professional applications. Usually each faculty member makes these course decisions alone. Programs, like research proposals, improve dramatically when faculty members discuss these issues and solve programmatic challenges together.

\section{Teaching the Interdisciplinarity of Kinesiology}

The term interdisciplinarity emphasizes the integration of two or more disciplines at a level of deep understanding (Lattuca, 2001). Currently, faculty are focusing more intently on research interdisciplinarity, developing deep integrative networks of knowledge expertise and scientific instrumentation. Supporting interdisciplinarity requires time, thought, and often an overarching purpose that brings together two seemingly disparate research agendas (National Academies, 2005). Specialized interdisciplinary programs fostered at the university or college/school level provide degree and certificate opportunities for undergraduate and graduate students. There are additional ways, however, to think about this within departments by developing interdisciplinarity within courses or across courses taught within the same semester.

\section{Integrative Kinesiology}

There are many opportunities for interdisciplinarity within kinesiology. When teaching the graduate course, "Teaching Kinesiology to Undergraduate Students," at the University of Maryland, I had the opportunity to assist doctoral students from each department subdiscipline to understand how their content contributes to an integrative kinesiology. Among the projects in this three-credit course required of all doctoral students, includes the challenge to create a multilesson, interdisciplinary theme based unit for freshmen and transfer students in the 100 level "Introduction to Kinesiology" course. To complete this assignment, doctoral students form working teams with a representative from each department discipline. After much 
thought and discussion, team members collectively identify or select a thematic topic or issue in which each member possesses expertise. Examples have been: "How can kinesiology reduce the need for health insurance?"; "How to be Lance" (or Serena, Annika, or Marta); "How can kinesiology help individuals respond to the "medicalized' body?"; or "The good life at age 120!"

Then over a period of several weeks, graduate students in each team define student outcomes, collect or create resources, and organize their material for coherence. They next create three "real" lessons to teach undergraduates enrolled in Introduction to Kinesiology. The pedagogical kinesiology doctoral students studying learning theories and innovative instructional strategies assist their teams to structure problem solving approaches to content presentation across subdisciplines. They focus on the challenges of cognitive engagement and the deep disciplinary integrations needed to motivate undergraduate students, increase their sense of content ownership and enhance their abilities to work creatively and flexibly with kinesiology core content. Rather than teaching a complete lesson on the exercise physiology or the sport and exercise psychology of the theme or topic, I challenge doctoral teams to integrate the core knowledge within each lesson to enhance undergraduates understanding of the inherent relationships or connections between two or more disciplinary areas.

\section{Scheduling Considerations}

To coordinate this doctoral student teaching opportunity and to locate it within an authentic teaching environment requires preliminary work beginning a year in advance. Assistance is needed from administrators and colleagues to schedule the "Teaching Kinesiology to Undergraduates" and the "Introduction to Kinesiology" course sections to meet concurrently whenever possible. I also coordinate with the Introductory course instructors before the semester begins to interest them in allocating three lessons near the end of the semester to doctoral team teaching. In kinesiology majors with large enrollments, each interdisciplinary doctoral team can be assigned to a different "Introduction to Kinesiology" section and can observe at least one lesson taught by the Introductory course instructor before teaching their interdisciplinary lessons. Observation is critical to permit the doctoral teams to gauge lesson difficulty, presentation language and style, and room affordances, and to diffuse doctoral team members' stress and anxiety.

This integrative experience encourages the doctoral teams to attend to the connections rather than the separations between their graduate disciplinary areas. They consult together as they experiment with constructivist curriculum and teaching approaches, learning to structure and explain their content so that the undergraduates can understand the problem to be solved, not as biomechanics or sociocultural studies, but as integrative kinesiology.

\section{Kinesiology Climbs Mt. Everest}

One interdisciplinary doctoral student team, for example, asked undergraduates to consider the kinesiological challenges faced by a paraplegic climber on his well-publicized attempt to scale Mt. Everest. After first introducing and framing the problem using Sports Illustrated articles documenting the event, the motor behaviorist on the team discussed the challenge of creating prosthetic climbing 
legs that could withstand the assent in the very cold environment. Over the three lessons, the exercise physiologist added information on the training regimen necessary to prepare for the high-altitude climb, asked the undergraduates to provide training recommendations based on assigned readings, and encouraged discussion of possible training differences for the disabled and able-bodied climbers. The sport and exercise psychologist discussed factors such as motivation, stresses inherent in this life-threatening activity both for the disabled climber and the large team of support climbers, and effects of these individual challenges on team building for the entire group. The critical cultural studies team member first helped undergraduates to understand embodiment and then asked undergraduates to compare differences in the embodied experiences of the disabled and the able-bodied climbers.

After the graduate presenters and their undergraduate students discussed these topics as celebrations of this fabulous climbing accomplishment, the critical cultural studies team member again stepped to the front of the room and asked undergraduates to think reflectively about whether this endeavor should ever have been attempted ... "How did this severe environment and the needs of the disabled climber place the supporting team members at great risk of losing their own lives in what some might describe as a media 'stunt'?" Not only were the undergraduates caught up in the richness of the integrative discussions, they realized, perhaps for the first time, the power of kinesiology to address interesting and important global topics.

While the climber's story attracted them to the lessons, the diverse, yet coherently presented information, increased their understanding and excitement about the kinesiology content they soon would be learning in their core courses. As the graduate course instructor, my role was to set the plan in motion and then step to the side. The graduate students' interest lifted them to a deeper understanding of undergraduate pedagogy than I could ever have achieved in a lecture. They worked harder on the project because of its intrinsic value than they ever would have worked for the grade, alone. Likewise, the Introduction to Kinesiology course instructors reported that the undergraduates benefited so much more from this dynamic presentation than bringing in faculty members to talk about each discipline in isolation. The peer teaching, near pear mentoring, and peer assisted learning strategies were exceptionally effective in communicating the interdisciplinarity of the kinesiology content.

\section{Fostering Conceptual Transfer}

Once we have first semester undergraduates excited about the knowledge base of an integrated kinesiology, how do we carry this momentum forward into our kinesiology core courses? Many of these courses are placed or sequenced in the program with the assumption that students will learn fundamental theories and concepts necessary for advanced understandings and/or application in professional field experiences, such as those included in teacher education, athletic training, and fitness specializations (Darling-Hammond \& Bransford, 2005). Nevertheless, when professional and core course faculty discuss the extent to which students remember and transfer disciplinary content to other courses, they are often disappointed by how little students can actually recall and apply. 


\section{Types of Transfer}

In teacher education, for example, majors take core courses in motor development, learning, and control (or some combination) as prerequisites to elementary and secondary teaching courses. Yet, often majors never focus on the transfer of child and adolescent development content to their students' ability to participate successfully in a progression of increasingly more complex games. Often this is not attributable to the null curriculum (content not taught), but is more likely associated with the complexity of the "far" transfer requirements of the task (Salomon \& Perkins, 1989). In kinesiology, the foundational concepts and principles as taught and assessed in core courses may have little resemblance to the actual application tasks required in professional courses.

Both core and professional course instructors can assist students to transfer fundamental concepts by using a variety of research-supported pedagogical strategies that facilitate far transfer. Alexander (2006) distinguishes between near and far transfer based, in part, on the level of resemblance of the foundational concept in its initial presentation with later presentations of the concept in application tasks. When students are asked to replicate procedures to generate answers to similar problems in theoretical or laboratory contexts, they are less likely to learn how to generate creative or novel solutions in the field (e.g., Sternberg, 2003). This is an example of entrenched strategies in which students have been taught too well. In this case near transfer strategies become obstacles to deeper forms of transfer (Alexander, 1997). Near transfer is "a mindless transfer of the nearest kind achieved by the continued, routine practice of problem-solving skills" in similar situations (Alexander, 2006, p. 140). Near transfer tasks replicate surface similarities and have consistent and predictable underlying processes and procedures. Near transfer is obvious, logical, and often effortless.

\section{Teaching for Far Transfer}

Conversely, far transfer requires mindful and reflective exploration of complex problems encountered from diverse perspectives in varied contexts (Alexander, 2006). Students who participate in courses in which far transfer is the objective increase their ability and willingness to give effort to solve more meaningful and application relevant content problems (Thagard, 1991). They focus purposefully on reasoning, reading for comprehension, and the use of meta-cognitive or selfregulatory strategies that dramatically increase the likelihood of concept transfer and problem solution. Alexander points out strategies proven to facilitate far transfer. Implementing these strategies in core, advanced, and professional courses can increase students' focus on foundational concepts and assist them to apply the concepts and principles as a springboard to more advanced knowledge and effective application. In this section, I will discuss briefly several strategies critical to intentional concept transfer. These include (a) adequate instructional time, (b) multiple and varied far transfer opportunities, (c) concept proximity, (d) instructional focus, (e) analogical thinking, (f) peer dialogue, (g) concept value, and (h) rewards for far transfer (Alexander, 2006).

Adequate Instructional Time. Instruction explicitly designed to facilitate far transfer should provide adequate time for and attention to the central, foundational 
concepts that support productive decision-making within the discipline. When courses and programs are revised to foster far transfer, faculty chose to omit less critical content or divide the course into two, permitting the instructor to cover content slowly, in more depth, and with the expectation of a higher level of student understanding (Salomon \& Perkins, 1989). Instructors also can increase student concept understanding by allocating time proportionally to the magnitude or value of the foundational concept.

Multiple and Varied Transfer Opportunities. Instructional time alone, however, is not adequate to produce far transfer. Core courses designed with the purpose of stimulating far transfer also need to include many different types of transfer tasks. Although science-related courses include laboratories to increase in-depth learning within the discipline, instructors rarely ask students to apply the concepts outside the laboratory in professionally related tasks that can be immediately relevant and meaningful to students (Greeno, Smith, \& Moore, 1996). Core course instructors, for example, might ask students to think about their personal experiences, discussing how the concept facilitates performance in a well-understood sport or fitness activity. Similarly they could assign students to interview or assess the concept or principle as it relates to friends' or family members' physical activity to understand factor variability in a small, but personally meaningful, subset of the population.

Course Proximity Placing courses that teach the same foundational concepts and principles in close proximity within the program sequence also can increase far transfer. Courses taught as corequisites instead of prerequisites can enhance student opportunities for meaningful applications. Core and application course instructors coordinate the timing of concept presentation to occur simultaneously or consecutively to assist students to focus on relevant applications of foundational knowledge. This can minimize students' need to memorize materials, instead learning deeply through both fundamental and applied tasks.

Pairing core/application courses and coordinating course projects requires more faculty conversation than teaching the course in isolation. It creates opportunities for faculty discussion and for students to experience immediate, authentic applications that increase students' depth of understanding. This design is quite effective for courses that teach concepts and principles essential in far transfer applications focusing directly on human sport and exercise. Planned redundancy through course placement and instructor collaboration can lead to student "ah-ha!" experiences. Students learn quickly to look for application and transfer opportunities when they realize that instructors have intentionally embedded these in their courses.

Far transfer requires that instructors intentionally present foundational concepts in multiple forms and varying contexts (Salomon \& Perkins, 1989). Students can be challenged to solve similar problems using several different strategies within and across courses. To encourage far transfer, instructors should revisit fundamental concepts frequently, in diverse ways, in multiple courses, and varying contexts, promoting reflection and analysis for undergraduate and graduate learners.

Enhanced Instructional Focus. Both students and instructors need to concentrate their cognitive energies on identifying and applying foundational concepts and principles. Research documents instances in which instructors' attempts to interest or entertain students inadvertently distract and disrupt students' focus on foundational concepts (Gelman \& Greeno, 1989). Instead, instructors can increase the 
potential for student transfer by avoiding "great stories" while explicitly pointing out similarities and differences between or among concepts or situations conducive to concept applications. Instructors can facilitate far transfer through efforts to focus tightly on salient concept features, building relationships directly to varied and complex applications.

Analogical Reasoning. Analogical reasoning is based on the process of discerning relationships between seemingly dissimilar ideas or events (Alexander, 2006). Applying known characteristics to novel phenomenon can lead to a deeper understanding of the new content and the process through which the two can be compared. Helping students identify similar and dissimilar characteristics is critical to problem solution. If students fail to see the similarities between particular tasks or contexts, it is unlikely they will engage in mindful transfer of conceptual or procedural knowledge across tasks or contexts (Kolodner, 1997). The more comfortable students are with reflective and comparative thinking, the more aware they are of procedures that facilitate transfer (Reeves \& Weisberg, 1994).

Bridging and Prompting. Although some students can learn to compare similar contexts or concepts without instructor assistance, the process occurs more smoothly, predictably, and effectively when tasks or courses are arranged intentionally to bridge concepts across contexts (Garner, 1990). Scheduling courses that rely on a common set of foundational concepts during the same or successive semesters can set up the bridging process. Instructors teaching specifically for far transfer focus students' attention on the relationships, assisting them to bridge the courses by providing specific pathways from the disciplinary course to the advanced or application course.

Instructor reminders or prompts emphasizing the relationships among the concepts, tasks, and examples can explicitly frame relationships, leading directly to far transfer opportunities. According to Alexander and Murphy (1999), bridging and prompting are tools that instructors use to model the reflective, problem-solving process. These techniques signal to students that comparative and integrative thinking is valued in these courses. Bridging and prompting techniques can be used to link content from previous to current courses, in school to internship settings, and lecture to laboratory tasks. Faculty efforts to locate and coordinate explicit bridging and prompting opportunities can increase the value of course co- and prerequisites. Likewise, instructor satisfaction increases when students make critical linkages within the subject matter necessary to move to more advanced understandings and concepts.

Peer Dialogue Although some scientists prefer to work alone in the laboratory, most find that opportunities to work with knowledgeable colleagues who challenge and test their ideas are of great advantage. Opportunities for dialogue about foundational concepts are critically important in knowledge advancement. The same is true for students who are engaging with new concepts and relationships for the first time. Cognitive psychologists are increasingly acknowledging the valuable role that peer conversation has in facilitating far transfer (Alexander, 2006). Dialogue with peers to discuss results, consider alternatives, or test predictions provides multiple benefits that facilitate transfer and application. One of the advantages of shared learning is the requirement that students make their ideas public, working to make them understandable to peers, while reconsidering connections and applications that make sense to peer critics. 
Developing opportunities for student conversations about the content through laboratories, discussion groups, or through a five-minute class problem can dramatically improve student understanding and the ability to transfer concepts to other contexts and situations. When the core course goal is next level or professional concept transfer, it is very effective to permit and encourage open exchanges of ideas around complex and relevant problems to stimulating student interest and effort. Undergraduates enrolled in large lecture courses, in particular, benefit directly from shared learning tasks as they wake-up, engage socially with others, and hear diverse perspectives in a different voice than that of the instructor.

Enhancing Student Value for the Concept. Far transfer requires student mindfulness, motivation, and intention. It is unlikely that students will transfer knowledge, even under the most ideal instructional settings, if they do not first recognize the value or usefulness of the foundational knowledge. Far transfer is a form of learning that requires cognitive effort, knowledge synthesis, self-regulatory strategies, and student motivation. These can occur simultaneously in complex instructional environments as instructors frame the task, monitor learners, and engage and reengage students in a context that lends itself to far transfer. These components are the seeds of far transfer that encourage diverse learners to apply foundational concepts in relevant and meaningful settings (Alexander \& Murphy, 1999).

Valuing and Rewarding Transfer. Students need to know that instructors will value and reward their efforts at transfer. As students are introduced to foundational concepts in some large kinesiology core courses, they often are asked to memorize and repeat the knowledge on short answer quizzes or multiple-choice examinations. Students determine quickly what forms of knowledge instructors' value in the classroom and adjust rapidly to simply memorize, replicate, or perform near transfers, depending on the assessment (Alexander, 2006). They are very strategic in their use of study time and can conform efficiently to the instructor and course demands.

Curricular designs that include relevant, in-depth problem solving and far transfer challenges can convert students from memorizers to problem solvers. Creating and positioning courses to affirm these strategies taught by instructors committed to far transfer can transform program dynamics and increase instructor satisfaction with increased levels of student engagement and learning. Further, students, themselves, perceive that courses are more challenging, more worthwhile, and more closely related to their career goals. Redesigning courses for far transfer enhances student interest and motivation, increasing their understanding of foundational concepts that are stepping stones to more advanced knowledge.

\section{Conclusion}

As universities adjust to changing economies, departmental administrators and faculty have an opportunity to evaluate current program offerings for relevance and coherence. Opportunities to create integrative degrees, such as professional masters, open potential revenue sources that can attract and retain new students. Within the department or program, course realignment can result in more effective use of faculty and student time with a greater emphasis on content directly relevant to student needs and interests, enhancing retention and graduation rates. Opportunities also exist to teach kinesiology as an interdisciplinary body of knowledge. This 
requires new ways of thinking about the relationships inherent among our valued subdisciplines. Of utmost importance is the need to design core and foundation courses to promote transfer.

Teaching to facilitate far transfer is particularly important for mid and lower GPA students. These students often need additional help identifying connections between and among foundational concepts and between foundational knowledge and the complex situation or context in which they typically are applied. Transfer strategies also hold promise for engaging faculty in course reflection that can lead to both deeper student learning and course satisfaction. The opportunity for faculty to engage in coordinated curriculum planning based on proven researchbased strategies can provide exceptional benefits for undergraduate and graduate students.

Transfer is the quintessence of effective instruction. Whether the foundational knowledge is intended for application or for the development of more complex concepts and principles, conceptual transfer is essential for continued learning. Of all the changes, adjustments, and revisions that can be made in program design, assisting instructors to design and teach for far transfer may be the most vital in increasing student satisfaction, retention, and learning.

\section{References}

Alexander, P.A. (1997). Knowledge seeking and self-schema: A case for the motivational dimensions of exposition [Special issue]. Educational Psychologist, 32, 83-94.

Alexander, P.A. (2006). Psychology in learning and instruction. Upper Saddle River, NJ: Pearson.

Alexander, P.A., \& Murphy, P.K. (1999). Nurturing the seeds of transfer: A domain-specific perspective. International Journal of Educational Research, 31, 561-576.

Benderly, B.L. (2008, March 7). Mastering the job market. Science. Retrieved from http://sciencecareers.sciencemag.org/career_development/previous_issues/ articles/2008_03_07/caredit_a0800033

Benderly, B.L. (2009, July 3). Taken for granted: An alternative to the Ph.D. tract. Science. Retrieved from http://sciencecareers.sciencemag.org/career_magazine/previous_issues/ articles/2009_07_03/caredit.a0900083

Colwell, R.R. (2009). Professional science master's programs merit wider support. Science, $323,1676-1677$.

Council of Graduate Schools. (2009a). CGS professional master's in social sciences and humanities initiative. Retrieved from http://www.cgsnet.org/Default.aspx?tabid=121

Council of Graduate Schools. (2009b). Professional science master's update: The internship component. Communicator, 42, Retrieved from http://www.cgsnet.org.

Council of Graduate Schools. (2009c, June 29). Report of the first commission meeting. Commission on the future of graduate education. Retrieved from: http://www.cgsnet. org/Default.aspx?tabid=387

Darling-Hammond, L., \& Bransford, J. (Eds.). (2005). Preparing teachers for a changing world: What teaches should learn and be able to do. San Francisco: Jossey-Bass.

DePauw, K.P. (2008). Graduate education in Kinesiology: Are we part of "America's backbone for competitiveness and innovation? Quest, 60, 131-138.

Fischer, K., \& Glenn, D. (2009, Aug. 31). Five college majors on the rise. The Chronicle of Higher Education, LVI. Retrieved from http://chronicle.com/article/5-College-MajorsOn-the-Rise/48207/

Flinders, D.J., Noddings, N., \& Thornton, S.T. (1986). The null curriculum: Its theoretical base and practical implications. Curriculum Inquiry, 16, 33-42. 
Garner, R. (1990). When children and adults do not use learning strategies: Toward a theory of setting. Review of Educational Research, 60, 517-529.

Gelman, R., \& Greeno, J.G. (1989). On the nature of competence: Principles for understanding in a domain. In L.B. Resnick (Ed.), Knowing, learning, and instruction: Essays in honor of Robert Glaser (pp. 125-186). Hillsdale, NJ: Erlbaum.

Glenn, D., \& Fischer, K. (2009, Aug. 31). The canon of college majors persists amid calls for change. The Chronicle of Higher Education, LVI. Retrieved from http://chronicle. com/article/Amid-Calls-for-Change-Coll/48206/

Greeno, J.G., Smith, D.R., \& Moore, J.L. (1996). Transfer of situated learning. In D.K. Detterman \& R.J. Sternberg (Eds.), Transfer on trial: Intelligence, cognition, and instruction (pp. 99-167). Norwood, NJ: Ablex.

Kolodner, J.L. (1997). Educational implications of analogy: A view from case-based reasoning. The American Psychologist, 52, 57-66.

Labi, A. (2009, Sept. 18). European universities look overseas for new partnerships. The Chronicle of Higher Education, LVI. Retrieved from http://chronicle.com/article/ European-Universities-Look-/48366/

Lake, P.F. (2009, Aug. 11). Will your college be sued for educational malpractice. The Chronicle of Higher Education, Retrieved from http://chronicle.com/article/EducationalMalpractice-Ma/47980/

Lattuca, L.R. (2001). Creating interdisciplinarity: Interdisciplinary research and teaching among college and university faculty. Nashville: Vanderbilt University Press.

Loades, R. (2005, Jan.-Feb.). The Bologna Accord: A European revolution with global implications Graduate Management News. Retrieved from http://www.gmac.com/gmac/ NewsandEvents/GMNews/2005/JanFeb/BolognaAccord.htm?Page=1

National Academies. (2005). Facilitating interdisciplinary research. Washington, DC: The National Academies Press.

Reeves, L.M., \& Weisberg, R.W. (1994). The role of content and abstract information in analogical transfer. Psychological Bulletin, 115(3), 381-400.

Salomon, G., \& Perkins, D. (1989). Rocky roads to transfer: Rethinking mechanisms of a neglected phenomenon. Educational Psychologist, 24, 113-142.

Schmidt, P. (2009, Sept. 15). Harvard offers new doctorate for school leaders who aim to shake up status quo. The Chronicle of Higher Education, LVI. Retrieved from http:// chronicle.com/article/Harvard-Offers-New-Doctorat/48411/

Spencer, H. (1861). Education, intellectual, moral and physical. London: Williams \& Norgate.

Sternberg, R.J. (2003). Who is an expert student? Educational Researcher, 32(8), 5-9.

Thagard, P. (1991). Concepts and conceptual change. In J.H. Fetzer (Ed.), Epistemology and cognition (pp. 101-120). Dordrecht, Netherlands: Kluwer.

Tobias, S. (2009, June 20). Professional science degree may be $21^{\text {st }}$ century MBA. Science News. Retrieved from www.sciencenews.org.

Wilson, D.A. (2005). GMAC Bologna report. Retrieved from http://www.gmacbolognaproject.com/ 